\title{
Inhibitory effect of carboplatin in combination with bevacizumab on human retinoblastoma in an in vitro and in vivo model
}

\author{
QI ZHANG ${ }^{1-3 *}$, YONG CHENG ${ }^{1-3^{*}}$, LVZHEN HUANG $^{1-3}$, YUJING BAI $^{1-3}$, JIANHONG LIANG $^{1-3}$ and XIAOXIN LI ${ }^{1-3}$ \\ ${ }^{1}$ Department of Ophthalmology, The People's Hospital, Peking University; ${ }^{2}$ Key Laboratory of Vision Loss \\ and Restoration, Ministry of Education; ${ }^{3}$ Beijing Key Laboratory of Diagnosis and Therapy of Retinal \\ and Choroid Diseases, The People's Hospital, Peking University, Beijing 100044, P.R. China
}

Received August 26, 2015; Accepted January 6, 2017

DOI: $10.3892 / \mathrm{ol} .2017 .6827$

\begin{abstract}
Retinoblastoma is the most common type of malignant intraocular tumor in children, and angiogenesis is required for tumor growth and expansion. The present study investigated whether use of the vascular endothelial growth factor inhibitor antibody bevacizumab can increase the inhibitory effect of carboplatin on human retinoblastoma Y79 cells. This was investigated using in vitro and in vivo models. Cell proliferation was assayed using a Cell Counting Kit-8 assay, which tested different concentrations of carboplatin in combination with bevacizumab. Cell apoptosis and cell cycle were analyzed using flow cytometry. Protein levels of related signaling pathway molecules were determined by western blotting. The present study used an intravitreal retinoblastoma mouse model for the in vivo study $(\mathrm{n}=40)$. Tumors were analyzed histologically. The present study revealed that combining bevacizumab and carboplatin in an in vitro culture of Y79 cells led to a higher inhibition of cellular proliferation than carboplatin alone $(\mathrm{P}<0.05)$. The drug combination caused increased apoptosis, and a greater inhibition of the phosphoinositide 3-kinase (PI3K)/protein kinase B (Akt) and mitogen activated protein kinase (MAPK)/extracellular signal-regulated kinase (ERK) pathways. This combination also effectively inhibited tumor growth in vivo $(\mathrm{P}<0.05)$. These results demonstrate that a combination of carboplatin and bevacizumab results in a greater antitumor effect in advanced human retinoblastoma in vitro and in vivo by inhibiting the PI3K/Akt and MAPK/ERK pathways.
\end{abstract}

Correspondence to: Professor Xiaoxin Li or Professor Jianhong Liang, Department of Ophthalmology, The People's Hospital, Peking University, 11 Xizhimen South Street, Beijing 100044, P.R. China E-mail: drlixiaoxin@163.com

E-mail: jianhongliang@hotmail.com

${ }^{*}$ Contributed equally

Key words: retinoblastoma, carboplatin, bevacizumab, monotherapy, combined therapy

\section{Introduction}

Retinoblastoma is the most common type of malignant intraocular tumor in children, and it affects $\sim 1$ in 16,000-18,000 births, with an incidence of 7,000-8,000 new cases per year worldwide (1-3). A total of $~ 80 \%$ of children with retinoblastoma are diagnosed prior to the age of 3 (4). Retinoblastoma treatment is administered according to the International Classification of Retinoblastoma (ICRB) (5). In developing countries, although current laser photocoagulation, thermotherapy and chemotherapy exhibit high survival rates, enucleation remains inevitable for children with advanced tumors (ICRB group D, E), including subretinal seedings and vitreous seedings (6). Therefore, combined treatments with increased efficiency \& reduced toxicity are required for advanced retinoblastoma.

Chemotherapy serves an important function in the management of retinoblastoma. Carboplatin is a platinum-based chemotherapy drug that stops tumor growth by directly attacking DNA repair (7). Since the late 1980s, this drug has been used to treat numerous types of solid cancer, including retinoblastoma (8). Current systemic chemotherapy for retinoblastoma consists of 6-10 cycles of carboplatin, vincristine and etoposide. To maximize the effectiveness and minimize the toxicity caused by exposure to systemic chemotherapy, local chemotherapeutic regimens can be delivered intra-arterially, transclerally or intravitreally. In 1996, Harbour et al (9) demonstrated that intravitreous injection of carboplatin caused retinoblastoma tumor regression in transgenic mice; later that year, Murray et al (10) obtained similar results. However, the rate of tumor control with monochemotherapy for advanced retinoblastoma in the clinic is low (11). Additional laboratory studies are required to combine other agents that act against tumorigenesis with carboplatin to optimize the therapeutic schedule for advanced retinoblastoma.

Tumorigenesis is a complex process involving angiogenesis. In the 1970s, Folkman et al (12) revealed anti-angiogenic therapy as a potential treatment for tumors. Compared with other angiogenic factors, several studies have demonstrated that vascular endothelial growth factor (VEGF) and its receptors (VEGFR) perform central roles in a variety of cancers. For intraocular tumors, intraocular VEGF levels were increased in the patients of uveal melanoma and retinoblastoma $(13,14)$. 
Based on these findings, a variety of anti-angiogenic drugs, including anti-VEGF antibodies such as bevacizumab and VEGF-receptor kinase inhibitors, have been developed and approved for the treatment of several types of cancer. Bevacizumab is a recombinant humanized monoclonal antibody and is the first commercially available angiogenesis inhibitor that blocks angiogenesis by inhibiting all forms of VEGF-A (15).

To date, there have been limited studies on combined chemotherapy and anti-angiogenic therapy for retinoblastoma. Therefore, the purpose of the present study was to investigate the effect of carboplatin (chemotherapy) in combination with bevacizumab (anti-angiogenic therapy) on human retinoblastoma in vitro and in vivo.

\section{Materials and methods}

Cell culture and hypoxic treatment. The human retinoblastoma tumor Y79 cell line was obtained from the American Tissue Culture Collection (Manassas, VA, USA) and was cultured in RPMI-1640 with $10 \%$ fetal bovine serum (FBS; Gibco; Thermo Fisher Scientific, Inc., Waltham, MA, USA), $100 \mathrm{U} / \mathrm{ml}$ penicillin and $100 \mu \mathrm{g} / \mathrm{ml}$ streptomycin at $37^{\circ} \mathrm{C}$ in $5 \% \mathrm{CO}_{2}$ and $95 \%$ humidified air. For drug treatment, the cells were cultured at $37^{\circ} \mathrm{C}$ for an additional 24,48 or $72 \mathrm{~h}$ in a humidified-atmosphere incubator $\left(1 \% \mathrm{O}_{2}\right.$ and $\left.5 \% \mathrm{CO}_{2}\right)$.

Cell proliferation assay. Y79 cells were plated in 96-well plates at a density of $4 \times 10^{4}$ cells per well with $100 \mu \mathrm{l}$ of complete culture medium. Following proliferation for $24 \mathrm{~h}$, the cells were independently treated with 5 concentrations $(1,12.5,25,50$ and $100 \mu \mathrm{g} / \mathrm{ml}$ ) of carboplatin (Bristol-Myers Squibb GmbH \& Co. kGaA, München, Germany) and 3 concentrations (0.1, 1 and $2 \mathrm{mg} / \mathrm{ml}$ ) of bevacizumab (Roche Pharmaceutical, Shanghai, China), and were cultured at $37^{\circ} \mathrm{C}$ for another 24,48 or $72 \mathrm{~h}$ under hypoxic conditions; these experiments represented the monotherapy groups. For combined therapy, 5 concentrations $(1,12.5,25,50$ and $100 \mu \mathrm{g} / \mathrm{ml})$ of carboplatin in combination with 1 or $2 \mathrm{mg} / \mathrm{ml}$ of bevacizumab were added to cells, which were then cultured at $37^{\circ} \mathrm{C}$ for $48 \mathrm{~h}$ under hypoxic conditions. Wells with culture medium served as negative controls. At each time point, $10 \mu \mathrm{l}$ of Cell Counting Kit-8 (CCK-8) working solution (Dojindo Molecular Technologies, Inc., Shanghai, China) was added to each well prior to additional incubation for $2 \mathrm{~h}$ at $37^{\circ} \mathrm{C}$. The absorbance was recorded at $450 \mathrm{~nm}$ with an ELISA plate reader (Finstruments Multiskan Model 347; MTX Lab Systems, Inc., Vienna, VA, USA). All experiments were performed in 3 wells and were replicated at least 3 times.

Flow cytometry. The Y79 cell line was subject to an apoptosis study fluorescein isothiocyanate (FITC) Annexin V Apoptosis Detection kit; BD Biosciences, Franklin Lakes, NJ, USA) and cell cycle analysis (Cycletest Plus DNA Reagent kit; BD Biosciences), these were performed according to the manufacturer's protocol. Briefly, Y79 cells $\left(5 \times 10^{5} / \mathrm{ml}\right)$ with $1,000 \mu 1$ complete RPMI-1640 were seeded in 6-well plates and were incubated at $37^{\circ} \mathrm{C}$ for $48 \mathrm{~h}$ under hypoxic conditions with 5 concentrations $(1,12.5,25,50$ and $100 \mu \mathrm{g} / \mathrm{ml})$ of carboplatin, carboplatin plus $1 \mathrm{mg} / \mathrm{ml}$ bevacizumab, or with no additives as a control. The samples $\left(1 \times 10^{4}\right.$ cells $)$ were subsequently analyzed using flow cytometry (FACS Calibur; BD Biosciences) according to the manufacturer's protocol and as previously described (16). The apoptotic rate was calculated as the percentage of early apoptotic cells [FITC Annexin V positive and propidium iodide (PI) negative, LR] plus late apoptotic cells (FITC Annexin V positive and PI positive, UR). The cell cycle distribution of different groups was analyzed. The experiments were performed in triplicate and were repeated 3 times.

Transmission electron microscopy (TEM). The Y79 cells that were treated with $25 \mu \mathrm{g} / \mathrm{ml}$ of carboplatin alone or in combination with $1 \mathrm{mg} / \mathrm{ml}$ of bevacizumab and cultured at $37^{\circ} \mathrm{C}$ for $48 \mathrm{~h}$ under hypoxic conditions were fixed with $1.5 \%$ glutaraldehyde in $0.1 \mathrm{M}$ PBS ( $\mathrm{pH} \mathrm{7.0)}$ ) for $2 \mathrm{~h}$ at $4^{\circ} \mathrm{C}$. The cells were then post-fixed in $1 \%$ osmic acid in the same buffer, dehydrated in ethanol and embedded in epoxy resin. Thin sections (thickness, $70 \mathrm{~nm}$ ) were cut and were stained with toluidine blue. Finally, the sections were stained with uranium and lead prior to examination using TEM (FEI; Thermo Fisher Scientific, Inc.). The images were captured at magnifications of $x 2,550$ and $\times 8,200$ and were processed with graphics software (Adobe Photoshop CS5, Adobe Systems, Inc., San Jose, CA, USA).

Western blot analysis. The Y79 cells treated with 3 concentrations $(1,25$ and $100 \mu \mathrm{g} / \mathrm{ml})$ of carboplatin alone or in combination with $1 \mathrm{mg} / \mathrm{ml}$ of bevacizumab and cultured for $48 \mathrm{~h}$ under hypoxic conditions were washed with ice-cold PBS and were then prepared using radioimmunoprecipitation assay protein extraction buffer with a protease inhibitor cocktail (Pierce; Thermo Fisher Scientific, Inc.). The lysates were cleared by centrifugation at $15,000 \mathrm{xg}$ for $15 \mathrm{~min}$ at $4^{\circ} \mathrm{C}$. The supernatant was collected, and the protein content of each lysate was measured using a bicinchoninic acid protein assay kit (Pierce; Thermo Fisher Scientific, Inc.) according to the manufacturer's protocol. Equal amounts $(50 \mu \mathrm{g})$ of protein were loaded and separated by $10 \%$ SDS-PAGE prior to being transferred electrophoretically onto polyvinylidene difluoride membranes (GE Healthcare Life Sciences, Chalfont, UK).

Subsequent to blocking nonspecific binding with $5 \%$ skimmed milk, the membranes were incubated with rabbit polyclonal antibodies against phospho-(p-) extracellular signal-regulated kinases (ERK) 1/2 (catalog no. 4370; dilution, 1:1,000; Cell Signaling Technology, Inc., Danvers, MA, USA), ERK1/2 (catalog no. 9102; dilution, 1:1,000; Cell Signaling Technology, Inc.), p-protein kinase B (Akt; catalog no. 4060; dilution, 1:1,000; Cell Signaling Technology, Inc.) or Akt (catalog no. 4685; dilution, 1:1,000; Cell Signaling Technology, Inc.) followed by incubation with a horseradish peroxidase-conjugated goat antibody against rabbit (catalog no. 7074; dilution, 1:5,000; Cell Signaling Technology, Inc.). The proteins were visualized using enhanced chemiluminescence western blot detection reagents (Pierce; Thermo Fisher Scientific, Inc.). To ensure equal loading of the protein in each lane, the blots were stripped and re-probed with an antibody against $\beta$-actin (catalog no. 4087; dilution, 1:5,000; Cell Signaling Technology, Inc.), followed by incubation with a horseradish peroxidase-conjugated goat antibody against rabbit (catalog no. 707; dilution, 1:5,000; Cell Signaling 
Technology, Inc.). The intensity of protein bands was determined by ImageJ (version 2.0.0; National Institutes of Health, Bethesda, MA, USA). Western blot analyses were repeated 3 times, and similar results were obtained.

Animals and ethics statement. A total of $40 \mathrm{BALB} / \mathrm{c}$ nude female mice (Peking University Health Science Center, Beijing, China) that were 8 weeks old and weighed 18-20 g were used in the in vivo study. The left eyes $(\mathrm{n}=40)$ were injected for orthotopic retinoblastoma mouse model, as described below. All mice were housed under specific pathogen-free conditions in the Animal Facility of Peking University Health Science Center, with controlled humidity (between 40 and $70 \%$ ), at $24 \pm 1^{\circ} \mathrm{C}$, under $12 \mathrm{~h} \mathrm{light/dark} \mathrm{conditions,} \mathrm{and} \mathrm{with} \mathrm{food} \mathrm{and}$ water ad libitum.

This study adhered to The Association for Research in Vision and Ophthalmology Statement for the Use of Animals in Ophthalmic and Vision Research and was performed in accordance with the guidelines provided by the Animal Care Use Committee of Peking University.

Orthotopic retinoblastoma mouse model and drug treatment. Y79 cell suspensions $\left(5 \times 10^{5} / \mathrm{ml}\right)$ in PBS were used for intravitreous injection. Prior to cell injection, mice were anesthetized using intraperitoneal injections of ketamine $(50 \mathrm{mg} / \mathrm{kg}$ ) and xylazine $(5 \mathrm{mg} / \mathrm{kg})$. Subsequently, 1 drop of atropine was administered to dilate the pupil. Finally, a hamilton syringe with $2 \mu 1$ of cell suspension was inserted until the needle could be observed in the vitreous of the left eye through the microscope. The cell suspension was then slowly and carefully injected. The needle was removed 2 min subsequent to the injection, and 1 drop of erythromycin was administered to each eye. The eyes were then examined daily for leukocoria. Once tumor growth was detected, the mice were randomly divided into 2 groups: PBS intravitreous injection group and $5 \mu \mathrm{g}$ carboplatin with $1.25 \mu \mathrm{g}$ bevacizumab intravitreous injection group. Ocular images were captured at weeks 2, 4, 6 and $8(n=5)$ post-treatment for analysis.

Histopathological observation. Mice were euthanized with an overdose of ketamine and xylazine at different time points post-treatment, and the eyes were removed and dissected. Paraffin-embedded sections were then prepared from whole eyes. Serial sections $(5 \mu \mathrm{m})$ were stained with conventional hematoxylin and eosin (H\&E) staining, and the slides were then observed and photographed using a microscope (Olympus Corporation, Tokyo, Japan). All micrographs were taken under the same microscope with the same parameters (exposure time, $1 \mathrm{sec}$; resolution ratio, 1,280:960; brightness, $100 \%$ ) and were saved as TIFF files. The images were processed with graphics software (Adobe Photoshop CS5; Adobe Systems, Inc.).

Statistical analysis. Data analysis was performed using the statistical software Prism 5 (GraphPad Software, Inc., La Jolla, CA, USA). All data are presented as the mean \pm standard error of the mean and have been evaluated for normality of distribution. Differences between groups were evaluated with the Student's unpaired t-test (2-tailed). $\mathrm{P}<0.05$ was considered to indicate a statistically significant difference.

\section{Results}

Inhibition of Y79 cell proliferation by carboplatin and bevacizumab under hypoxic conditions. A CCK-8 measuring proliferation was used to evaluate the inhibitory effects of carboplatin and bevacizumab on Y79 cell proliferation in vitro under hypoxic culture conditions. Carboplatin inhibited Y79 proliferation in a time and dose-dependent manner (Fig. 1A, $\mathrm{P}<0.05)$. Bevacizumab significantly inhibited cell proliferation at high concentrations $(\geq 1 \mathrm{mg} / \mathrm{ml})$ following treatment for $72 \mathrm{~h}$ when compared with the 10\% FBS group (Fig. 1B, $\mathrm{P}<0.001)$. Since bevacizumab did not inhibit cell proliferation at other concentrations $(0.1,1$ and $2 \mathrm{mg} / \mathrm{ml})$ at 24 and $48 \mathrm{~h}$, the present study chose $1 \mathrm{mg} / \mathrm{ml}$ bevacizumab in combination with different concentrations of carboplatin at $48 \mathrm{~h}$ for the following experiments.

Inhibition of Y79 cell proliferation by carboplatin in combination with bevacizumab under hypoxic conditions. A total of 5 concentrations $(1,12.5,25,50$ and $100 \mu \mathrm{g} / \mathrm{ml})$ of carboplatin or carboplatin in combination with 1 or $2 \mathrm{mg} / \mathrm{ml}$ of bevacizumab were cocultured with Y79 cells for $48 \mathrm{~h}$ under hypoxic conditions. As shown in Fig. 1C, the combination group exhibited higher inhibition under hypoxic conditions in a time and dose-dependent manner $(\mathrm{P}<0.05)$. Subsequent to $48 \mathrm{~h}$ of exposure, an increased number of cells were swollen in the combined treatment group compared with either the carboplatin group or the PBS group (Fig. 1D).

Combination of carboplatin and bevacizumab induces $Y 79$ apoptosis, cell cycle arrest and morphological changes under hypoxic conditions. Flow cytometry tests were used to evaluate the effects of carboplatin alone and carboplatin plus bevacizumab on Y79 cell apoptosis (early apoptosis and late apoptosis) and on cell-cycle arrest ( $\mathrm{S}$ phase) under hypoxic conditions. In the present study, as presented in Fig. 2, there was a significant difference between the carboplatin plus bevacizumab group (Fig. 2B) and the carboplatin-alone group (Fig. 2A) in the apoptosis test (Fig. 2C; $\mathrm{P}<0.01$ ). Additionally, combination treatment (Fig. 2E) induced a greater degree of Y79 cell cycle arrest at S phase than the control group (Fig. 2D), and the difference was significant (Fig. 2F; P<0.05). A typical apoptotic body could be observed in the combined group (Fig. 2G, red arrow).

Combination of carboplatin and bevacizumab inhibited ERK $1 / 2$ and Akt signaling pathway phosphorylation. To examine the kinetics of ERK and Akt activation, cells were exposed to 3 concentrations $(1,25$ and $100 \mu \mathrm{g} / \mathrm{ml})$ of carboplatin alone or in combination with $1 \mathrm{mg} / \mathrm{ml}$ of bevacizumab for $48 \mathrm{~h}$ under hypoxic conditions. As shown in Fig. 3, the expression levels of phospho-ERK1/2 and phospho-Akt decreased significantly in the combination treatment group when compared to the carboplatin group, no change in the total levels of ERK1/2, Akt and $\beta$-actin was observed (Fig. 3A). Compared with the carboplatin group, significantly decreased expression of phospho-ERK1/2 and phospho-Akt in the combination treatment was also revealed by quantitative analysis of P-ERK1/2 and ERK1/2 expression relative to the controls (Fig. 3B; $\mathrm{P}<0.05$ ), and quantitative analysis of $\mathrm{P}-\mathrm{Akt}$ and Akt expression 

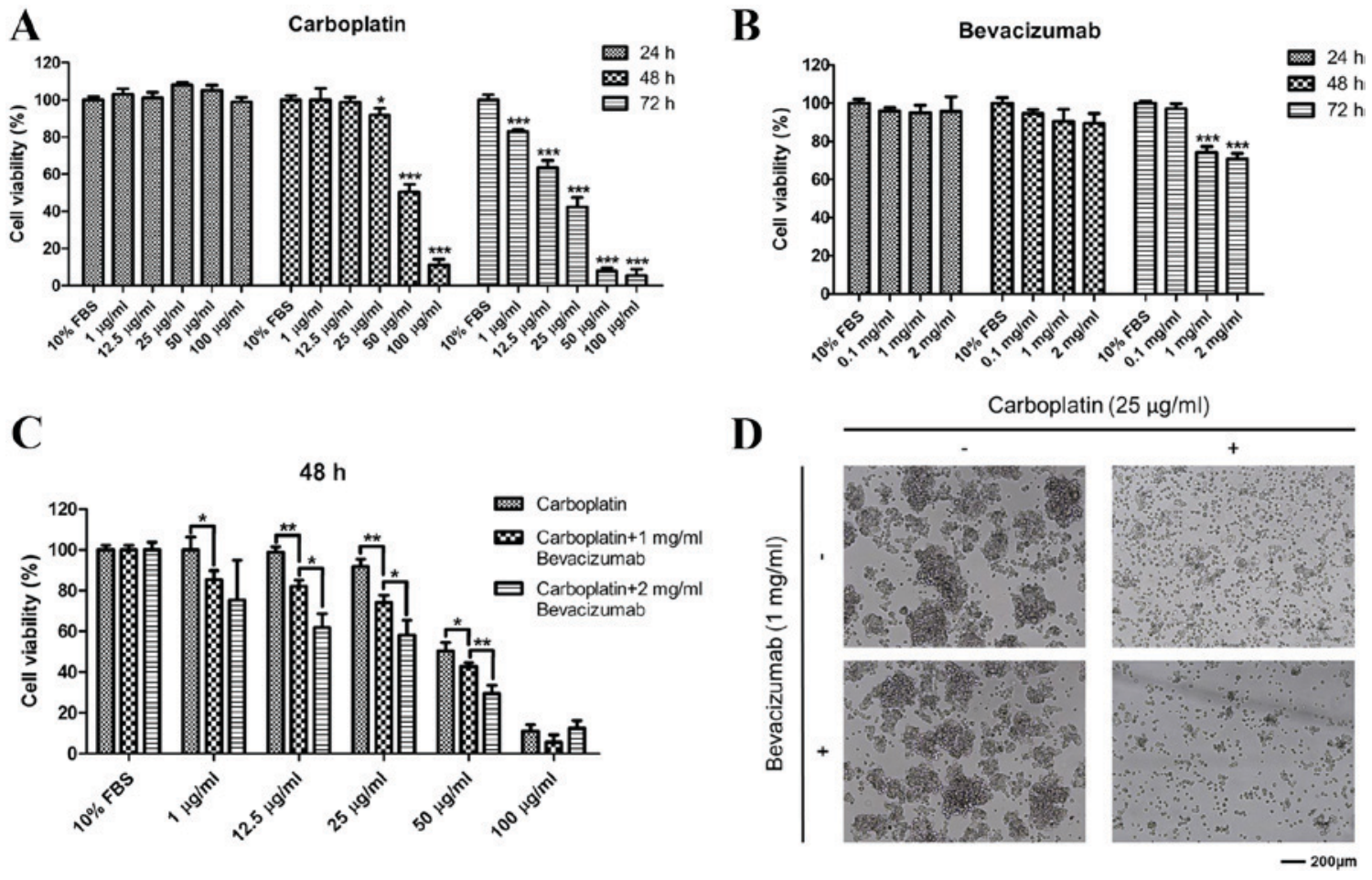

Figure 1. Inhibition of Y79 cell proliferation in monotherapy and combined therapy groups under hypoxic conditions. (A) Carboplatin inhibited Y79 proliferation in a time- and dose-dependent manner. (B) Bevacizumab significantly inhibited cell proliferation at high concentrations $(\geq 1 \mathrm{mg} / \mathrm{ml})$ following treatment for $72 \mathrm{~h}$, when compared with the $10 \%$ FBS group. (C) The combination group $(1,12.5,25,50$ and $100 \mu \mathrm{g} / \mathrm{ml}$ carboplatin in combination with $1 \mathrm{or} 2 \mathrm{mg} / \mathrm{ml}$ bevacizumab) exhibited higher inhibition under hypoxic conditions in a time- and dose-dependent manner. ${ }^{*} \mathrm{P}<0.05,{ }^{* * * *} \mathrm{P}<0.001$. (D) An increased number of cells exhibited swelling in the combined treatment group $(25 \mu \mathrm{g} / \mathrm{ml}$ carboplatin in combination with $1 \mathrm{mg} / \mathrm{ml}$ bevacizumab) compared with either the carboplatin group or the PBS group, visualized with fluorescence microscopy. Data are presented as the mean \pm standard error of the mean. Scale bar, $200 \mu \mathrm{m}$. FBS, fetal bovine serum.

relative to the controls (Fig. 3B; $\mathrm{P}<0.01$ ). These observations indicate that blockage of ERK1/2 and Akt activation partly contributed to the death of Y79 cells following treatment.

Combination of carboplatin and bevacizumab inhibits intravitreous tumorigenesis in mice. Following the present in vitro investigation of the antitumor effect of the combination of carboplatin and bevacizumab on Y79 cells and its mechanism, cells were injected into the vitreous cavity of BALB/c nude mice as an orthotopic retinoblastoma model. The present study used 2 groups of mice: PBS and the combination treatment. Drugs were administered every 2 weeks, and the longest diameter of the PBS-treated tumor (4 weeks: $8.9 \pm 0.34 \mathrm{~mm}$; 8 weeks: $10.2 \pm 0.85 \mathrm{~mm}$ ) and drug-treated tumor (4 weeks: $4.3 \pm 0.25 \mathrm{~mm} ; 8$ weeks: $5.2 \pm 0.78 \mathrm{~mm}$ ) were determined. Similar to the in vitro experiments, the combination of carboplatin and bevacizumab substantially suppressed tumor volume (Fig. 4A; $\mathrm{P}<0.05)$, whereas the average tumor volume in the PBS-treated eyes increased gradually with age (Fig. 4A).

Histological examination. To identify the tumor growth in the PBS-treated and drug-treated eyes, H\&E staining of orthotopic retinoblastoma model was performed. Compared with normal eyes at $x 4$ magnification (Fig. 4B) and $x 20$ magnification (Fig. 4E), the histological studies suggested that the drug-treated eyes at $\mathrm{x} 4$ magnification (Fig. 4C) and x20 magnification (Fig. 4F) exhibited a decreased tumor size; whereas the untreated eyes at $x 4$ magnification (Fig. 4D) and x20 magnification (Fig. 4G) contained numerous tumor cells with deeply stained nuclei and condensed cytoplasm.

\section{Discussion}

Retinoblastoma, the most frequent intraocular tumor in children, is treated according to its classification and severity. For children with advanced tumors, subretinal and vitreous seeding makes enucleation common for survival; therefore novel combined treatments are required.

Due to the limited number of retinoblastoma cases, cell lines and animal models have performed an important role in understanding retinoblastoma tumorigenesis and developing treatments. For advanced retinoblastoma, once cells are seeded into the vitreous cavity, they are kept in a suspended state. Therefore, the present study utilized suspended retinoblastoma Y79 cells. The Y79 cell line was the first retinoblastoma cell line and was derived from the tumor of a 2.5-year-old Caucasian female with a strong maternal history of retinoblastoma. It was also the first cell line transplanted into the anterior chamber of the nude mouse eye to establish a xenograft model of human retinoblastoma (17).

Angiogenesis is required for tumor growth and expansion. Previous studies have demonstrated that VEGF levels are significantly elevated in patients with retinoblastoma (18-20). Bevacizumab, an anti-VEGF agent, has been proven to affect the growth and differentiation of retinoblastoma cells in vitro $(21,22)$. In advanced retinoblastoma, the disseminated 

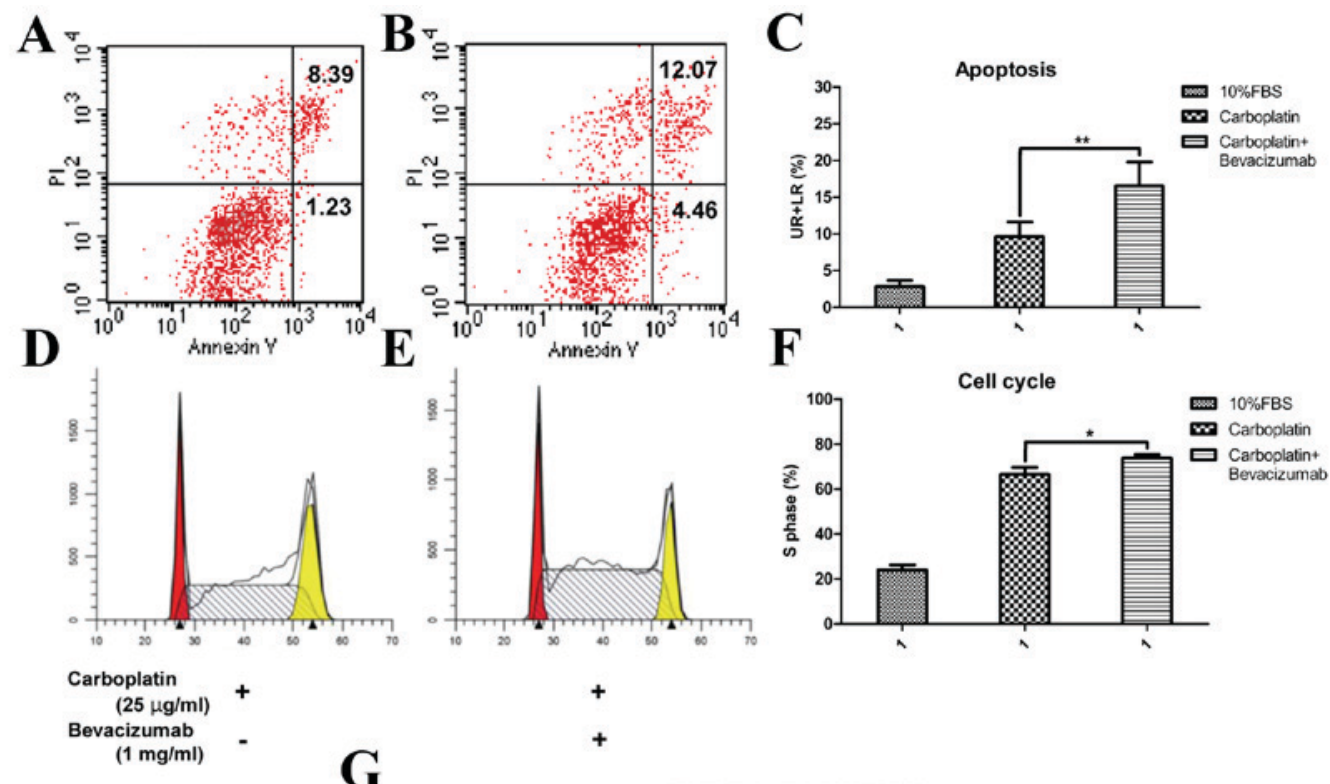

G
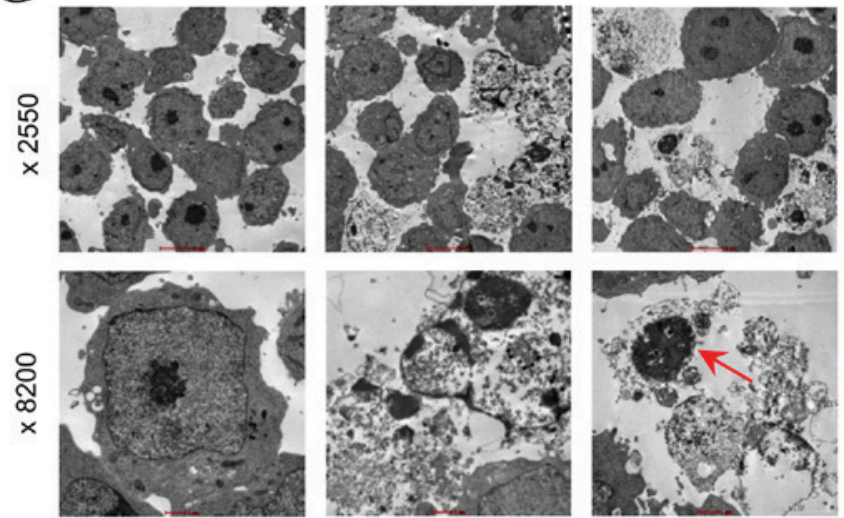

$\begin{gathered}\text { Carboplatin } \\ (25 \mu \mathrm{g} / \mathrm{ml})\end{gathered}$
Bevacizumab
$(1 \mathrm{mg} / \mathrm{ml})$

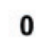

0

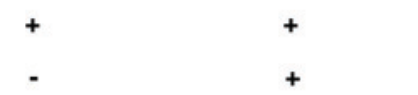

Figure 2. Combination of carboplatin and bevacizumab induced Y79 apoptosis, cell cycle arrest and morphological changes under hypoxic conditions (A) Frequency of Y79 cell apoptosis treated with $25 \mu \mathrm{g} / \mathrm{ml}$ carboplatin for $48 \mathrm{~h}$ for the monotherapy group was $9.62 \pm 1.4 \%$. (B) Frequency of Y79 cell apoptosis treated with $25 \mu \mathrm{g} / \mathrm{ml}$ of carboplatin plus $1 \mathrm{mg} / \mathrm{ml}$ of bevacizumab for $48 \mathrm{~h}$ for the combined treatment group was $16.53 \pm 2.3 \%$. (C) Frequency of Y79 cell apoptosis treated with combined therapy was significantly higher than the carboplatin monotherapy group. (D) Frequency of Y79 cell-cycle arrest under treatment with $25 \mu \mathrm{g} / \mathrm{ml}$ of carboplatin for $48 \mathrm{~h}$ in the monotherapy group was $66.47 \pm 2.22 \%$. (E) Frequency of Y79 cell-cycle arrest under treatment with $25 \mu \mathrm{g} / \mathrm{ml}$ of carboplatin plus $1 \mathrm{mg} / \mathrm{ml}$ of bevacizumab for $48 \mathrm{~h}$ for the combined treatment group was $73.79 \pm 1.14 \%$. (F) Frequency of Y79 cell-cycle arrest treated with combined therapy was significantly higher than the carboplatin monotherapy group, and more cells were blocked at S phase. Data are presented as the mean \pm standard error of the mean. Each experiment was performed in triplicate and was repeated 3 times. (G) Y79 cells treated with PBS, with $25 \mu \mathrm{g} / \mathrm{ml}$ carboplatin, or with $25 \mu \mathrm{g} / \mathrm{ml}$ carboplatin plus $1 \mathrm{mg} / \mathrm{ml}$ bevacizumab were examined using a TEM. A typical apoptotic body (red arrow) can be observed in the combined group. Scale bar, 5 and $1 \mu \mathrm{m}$. ${ }^{*} \mathrm{P}<0.05,{ }^{* *} \mathrm{P}<0.01$. PI, propidium iodide; FBS, fetal bovine serum; TEM, transmission electron microscope.

tumor cells are exposed to a hypoxic and nutrient-poor environment, which stimulates the tumor cells to secrete more angiogenic factors. Therefore, it was hypothesized that anti-VEGF therapy may have an important therapeutic role in advanced retinoblastoma. The present study treated Y79 cells (cultured under hypoxic conditions in vitro to mimic the advanced tumor microenvironment) with carboplatin plus bevacizumab. It was found that the carboplatin plus bevacizumab group inhibited Y79 cell proliferation and caused morphological changes. To further understand this inhibitory effect, the present study used flow cytometry to detect cellular apoptosis and analyze the cell cycle in the carboplatin-alone and combined-treatment groups. It was revealed that combination treatment induced greater cellular apoptosis and increased frequent cell-cycle arrest compared with monotherapy. These experimental results indicate that the carboplatin-and-bevacizumab combination results in a strengthened antitumor effect against human retinoblastoma cells in vitro.

Currently, there are limited studies on the mechanism of carboplatin and bevacizumab combination therapy. A previous study identified that VEGF-VEGFR2 is a key mediator for tumor angiogenesis and that VEGFR2 is expressed in Y79 cells (22). The present study analyzed common intracellular signaling pathways involved in VEGF-VEGFR2 signaling. Previous studies have demonstrated that the expression of phosphorylated ERK1/2 is necessary for cellular proliferation, and activation of the mitogen-activated protein kinase (MAPK)/ERK pathway is one of the hallmarks of cancer cells $(23,24)$. The PI3K/Akt pathway also serves a central 

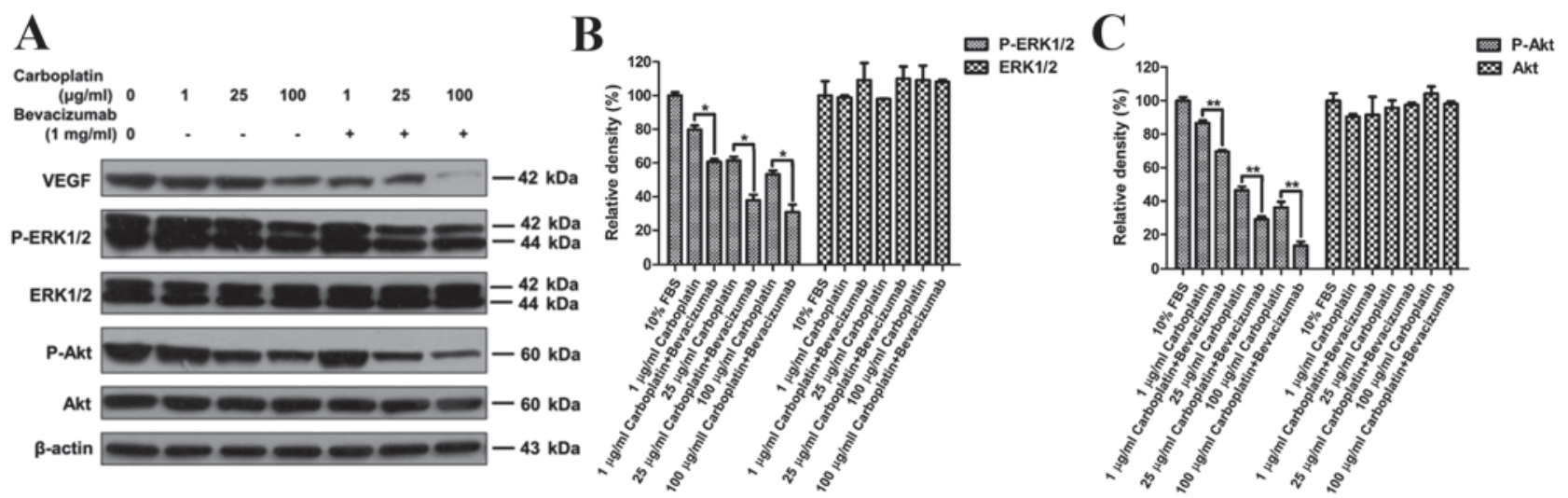

Figure 3. Combination of carboplatin and bevacizumab inhibited ERK1/2 and Akt signaling pathway phosphorylation. (A) The expression levels of phospho-ERK1/2 and phospho-Akt decreased significantly in the combination treatment group when compared to the carboplatin group, while no change in the total levels of ERK1/2, Akt and $\beta$-actin was observed. (B) Quantitative analysis of P-ERK1/2 and ERK1/2 expression relative to the controls proved the expression levels of phospho-ERK1/2 decreased significantly in the combination treatment group. (C) Quantitative analysis of P-Akt and Akt expression relative to the controls proved the expression levels of phospho-Akt decreased significantly in the combination treatment group. Data are presented as the mean \pm standard error of the mean. Each experiment was performed in triplicate and was repeated 3 times. ${ }^{*} \mathrm{P}<0.05$, ${ }^{* *} \mathrm{P}<0.01$. ERK, extracellular signal-regulated kinases; Akt, protein kinase B; VEGF, vascular endothelial growth factor; P-, phospho-; FBS, fetal bovine serum.
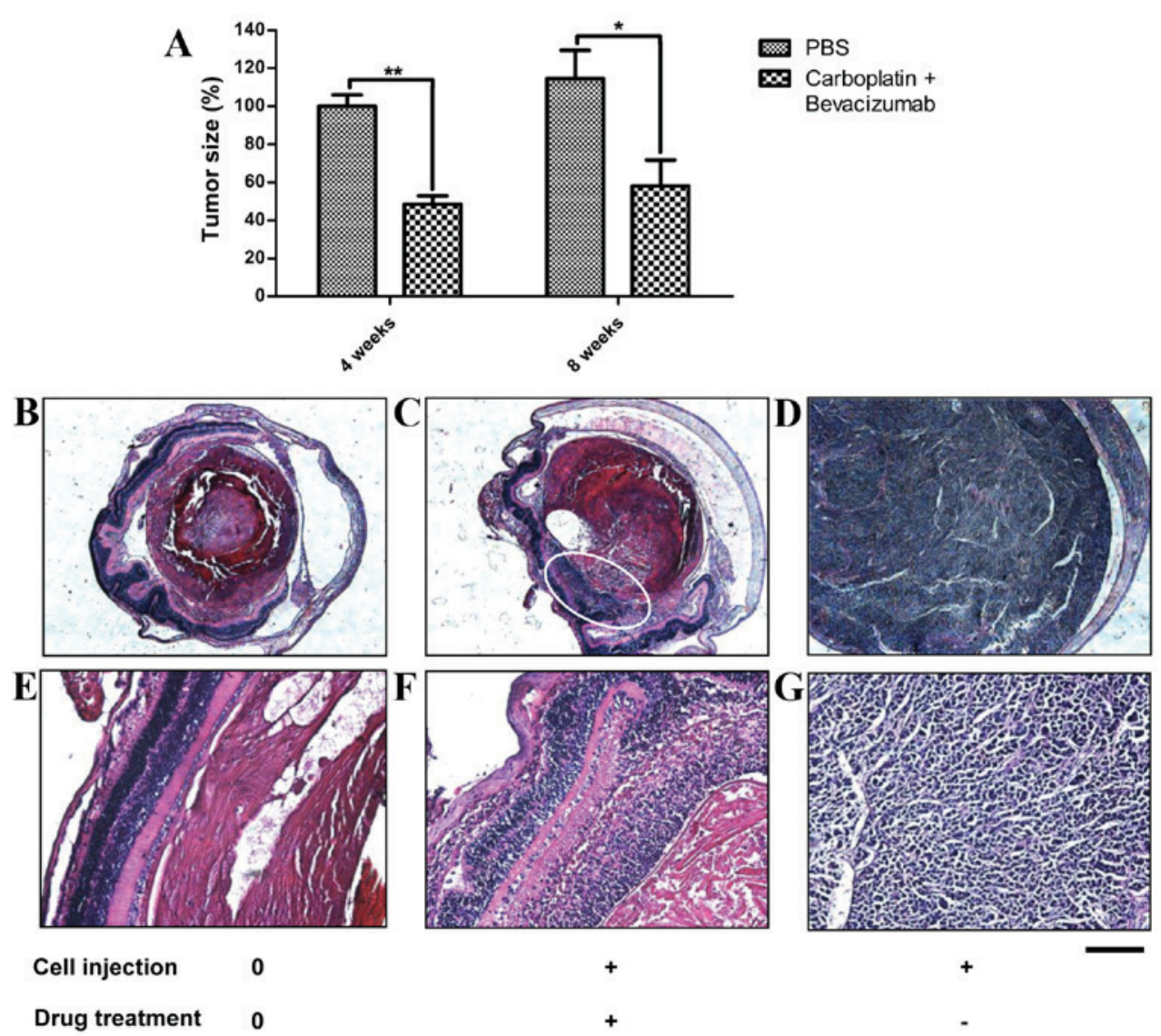

Figure 4. Combination of carboplatin and bevacizumab inhibited intravitreous tumorigenesis in nude mice. (A) Carboplatin and bevacizumab combined therapy significantly reduced tumor size compared to PBS-treated group. (B) Histological examination of normal eye (magnification, x4) showed normal eyeball structure. (C) Histological examination of eye treated with drugs following Y79 cell injection (magnification, x4) exhibited a decreased tumor size. (D) Histological examination of eye treated with PBS following Y79 cell injection (magnification, $x 4$ ) demonstrated that the eyeball was full of contained numerous tumor cells with deeply stained nuclei and condensed cytoplasm. (E) Histological examination of normal eye (magnification, x20) revealed normal retina structure. (F) Histological examination of eye treated with drugs following Y79 cell injection (magnification, x20) identified abnormal retina structure. (G) Histological examination of eye treated with PBS following Y79 cell injection (magnification, x20) demonstrated no retina structure. The drug-treated eyes had a reduced tumor size (4C, white circle) compared to PBS-treated eyes (4D). All data are presented as the mean \pm standard error of the mean. Scale bar, $100 \mu \mathrm{m}$ for B-D; $20 \mu \mathrm{m}$ for E-G. ${ }^{*} \mathrm{P}<0.05,{ }^{* *} \mathrm{P}<0.01$.

role in cell survival and proliferation and is aberrantly activated in numerous types of cancer (25). For these reasons, the MAPK/ERK and PI3K/Akt pathways are potential therapeutic targets for retinoblastoma. The present study revealed 
that the combined treatment reduced the increases of the expression of VEGF, phosphorylated ERK1/2 and Akt in the cells in vitro.

Compared to in vitro experiments, preclinical models have great advantages for tumor environment simulation and therapeutic evaluation. For additional in vivo study, the present study established an orthotopic retinoblastoma model by injecting cells into the vitreous cavity to mimic the advanced tumor microenvironment. The dose of drugs used in the present study was identical to that used for human patients, in association with body size. In 1993, Kim et al (26) confirmed that blood vessels are important for tumor growth and metastasis and that anti-VEGF treatment could inhibit the growth of human rhabdomyosarcoma, glioblastoma multiforme and leiomyosarcoma in nude mice models. Similarly, other studies have demonstrated that intraperitoneal injections of the anti-VEGF monoclonal antibody inhibits tumor growth in tumor-bearing nude mice and that VEGF-VEGFR2 signals perform a dominant role in tumor angiogenesis (27). The present results are consistent with these observations; in the present intravitreous model, carboplatin and bevacizumab combination therapy significantly inhibited the expression of VEGF and suppressed tumor growth in a time-dependent manner when compared with the control therapy.

Intraocular drug injection may cause secondary vitreous seeding, although the incidence is low. However, local application may significantly maximize the effectiveness of treatment and minimize the toxicity caused by exposure to systemic chemotherapy. Additional studies are required to optimize local therapy for retinoblastoma.

In summary, the present study was the first to confirm that a combination of carboplatin and bevacizumab results in a strengthened antitumor effect against human advanced retinoblastoma in vitro and in vivo and that the effect likely occurs via inhibition of the PI3K/Akt and MAPK/ERK pathways. Therefore, the present findings demonstrate that anti-angiogenic therapy may perform an adjuvant role in the treatment of advanced retinoblastoma.

\section{Acknowledgements}

The present study was supported by The Peking University People's Hospital Research and Development Fund (grant no. RDC-2014-24) and the National Basic Research Program of China (973 Program; grant no. 2011CB510200).

\section{References}

1. Broaddus E, Topham A and Singh AD: Incidence of retinoblastoma in the USA: 1975-2004. Br J Ophthalmol 93: 21-23, 2009.

2. Kivelä T: The epidemiological challenge of the most frequent eye cancer: Retinoblastoma, an issue of birth and death. Br J Ophthalmol 93: 1129-1131, 2009.

3. Seregard S, Lundell G, Svedberg H and Kivelä T: Incidence of retinoblastoma from 1958 to 1998 in Northern Europe: Advantages of birth cohort analysis. Ophthalmology 111: 1228-1232, 2004.

4. Chintagumpala M, Chevez-Barrios P, Paysse EA, Plon SE and Hurwitz R: Retinoblastoma: Review of current management. Oncologist 12: 1237-1246, 2007.
5. Shields CL, Mashayekhi A, Au AK, Czyz C, Leahey A, Meadows AT and Shields JA: The International classification of retinoblastoma predicts chemoreduction success. Ophthalmology 113: 2276-2280, 2006.

6. Balmer A, Zografos L and Munier F: Diagnosis and current management of retinoblastoma. Oncogene 25: 5341-5349, 2006.

7. Wheate NJ, Walker S, Craig GE and Oun R: The status of platinum anticancer drugs in the clinic and in clinical trials. Dalton Trans 39: 8113-8127, 2010.

8. Shields CL, Kaliki S, Rojanaporn D, Al-Dahmash S, Bianciotto CG and Shields JA: Intravenous and intra-arterial chemotherapy for retinoblastoma: What have we learned? Curr Opin Ophthalmol 23: 202-209, 2012.

9. Harbour JW, Murray TG, Hamasaki D, Cicciarelli N, Hernández E, Smith B, Windle J and O'Brien JM: Local carboplatin therapy in transgenic murine retinoblastoma. Invest Ophthalmol Vis Sci 37: 1892-1898, 1996.

10. Murray TG, Roth DB, O'Brien JM, Feuer W, Cicciarelli N, Markoe AM, Hernández E, Smith BJ and Windle JJ: Local carboplatin and radiation therapy in the treatment of murine transgenic retinoblastoma. Arch Ophthalmol 114: 1385-1389, 1996.

11. Gombos DS, Kelly A, Coen PG, Kingston JE and Hungerford JL: Retinoblastoma treated with primary chemotherapy alone: The significance of tumour size, location, and age. $\mathrm{Br} \mathrm{J} \mathrm{Ophthalmol} \mathrm{86:}$ 80-83, 2002.

12. Folkman J: Tumor angiogenesis: Therapeutic implications. $\mathrm{N}$ Engl J Med 285: 1182-1186, 1971.

13. Shibuya M: VEGF-VEGFR signals in health and disease. Biomol Ther (Seoul) 22: 1-9, 2014.

14. Missotten GS, Schlingemann RO and Jager MJ: Angiogenesis and vascular endothelial growth factors in intraocular tumors. Dev Ophthalmol 46: 123-132, 2010.

15. Bevacizumab. Anti-VEGF monoclonal antibody, avastin, rhumab-VEGF. Drugs R D 3: 28-30, 2002.

16. Bai YJ, Huang LZ, Xu XL, Du W, Zhou AY, Yu WZ and Li XX: Polyethylene glycol-modified pigment epithelial-derived factor: New prospects for treatment of retinal neovascularization. J Pharmacol Exp Ther 342: 131-139, 2012.

17. Reid TW, Albert DM, Rabson AS, Russell P, Craft J, Chu EW, Tralka TS and Wilcox JL: Characteristics of an established cell line of retinoblastoma. J Natl Cancer Inst 53: 347-360, 1974.

18. Areán C, Orellana ME, Abourbih D, Abreu C, Pifano I and Burnier MN Jr: Expression of vascular endothelial growth factor in retinoblastoma. Arch Ophthalmol 128: 223-229, 2010.

19. Youssef NS and Said AM: Immunohistochemical expression of CD117 and vascular endothelial growth factor in retinoblastoma: Possible targets of new therapies. Int J Clin Exp Pathol 7: 5725-5737, 2014

20. Cheng Y, Zheng S, Pan CT, Yuan M, Chang L, Yao Y, Zhao M and Liang J: Analysis of aqueous humor concentrations of cytokines in retinoblastoma. PLoS One 12: e0177337, 2017.

21. Lee SY, Kim DK, Cho JH, Koh JY and Yoon YH: Inhibitory effect of bevacizumab on the angiogenesis and growth of retinoblastoma. Arch Ophthalmol 126: 953-958, 2008.

22. Heo JW, Kim JH, Cho CS, Jun HO, Kim DH, Yu YS and Kim JH: Inhibitory activity of bevacizumab to differentiation of retinoblastoma cells. PloS one 7: e33456, 2012.

23. Shilo A, Ben Hur V, Denichenko P, Stein I, Pikarsky E, Rauch J, Kolch W, Zender L and Karni R: Splicing factor hnRNP A2 activates the Ras-MAPK-ERK pathway by controlling A-Raf splicing in hepatocellular carcinoma development. RNA 20: 505-515, 2014.

24. Hu Y, Yang H, Lu XQ, Xu F, Li J and Qian J: ARHI suppresses pancreatic cancer by regulating MAPK/ERK $1 / 2$ pathway. Pancreas 44: 342-343, 2015.

25. Georgakis GV and Younes A: From Rapa Nui to rapamycin: Targeting PI3K/Akt/mTOR for cancer therapy. Expert Rev Anticancer Ther 6: 131-140, 2006.

26. Kim KJ, Li B, Winer J, Armanini M, Gillett N, Phillips HS and Ferrara N: Inhibition of vascular endothelial growth factor-induced angiogenesis suppresses tumour growth in vivo. Nature 362: 841-844, 1993.

27. Mordenti J, Thomsen K, Licko V, Chen H, Meng YG and Ferrara N: Efficacy and concentration-response of murine anti-VEGF monoclonal antibody in tumor-bearing mice and extrapolation to humans. Toxicol Pathol 27: 14-21, 1999. 